\title{
Comparison of salivary levels of mucin and amylase and their relation with clinical parameters obtained from patients with aggressive and chronic periodontal disease
}

\author{
Andrea Beatriz ACQUIER ${ }^{1,2}$, Alejandra Karina De Couto PITA', Lucila BUSCH${ }^{1}$, Gabriel Antonio SÁNCHEZ ${ }^{3}$
}

\footnotetext{
1- Department of Pharmacology, Faculty of Dentistry, University of Buenos Aires, Buenos Aires, Argentina.

2- INBIOMED, National Scientific and Technical Research Council, Buenos Aires, Argentina.

3- Department of Biophysics, Faculty of Dentistry, University of Buenos Aires, Buenos Aires, Argentina.
}

Corresponding address: Gabriel A. Sánchez - Department of Biophysics - Faculty of Dentistry, University of Buenos Aires

Marcelo T. de Alvear 2142 (1122AAH) - Buenos Aires - Argentina - Phone: +54 1149641298 - Fax: +54 1145083958 - e-mail: gabriel@odon.uba.ar

Submitted: November 21, 2014 - Modification: February 11, 2015 - Accepted: March 15, 2015

\section{ABSTRACT}

\begin{abstract}
O bjective: Salivary mucin and amylase levels are increased in patients with chronic periodontitis (CP). Due to the fact that aggressive periodontitis (AgP) not only differs from chronic periodontitis in terms of its clinical manifestation, the aim of this study was to compare salivary mucin and amylase levels and their relation to the clinical parameters of patients with aggressive periodontitis with that of patients with chronic periodontitis. Material and Methods: Eighty subjects were divided into two groups: 20 patients with AgP and their 20 matched controls and 20 patients with CP and their 20 matched controls, based on clinical attachment loss (CAL), probing pocket depth (PPD) and bleeding on probing (BOP). Whole unstimulated saliva was obtained and mucin, amylase and protein were determined by colorimetric methods. Pearson's correlation analysis was used to determine the relationship between salivary mucin, amylase and protein levels and the clinical parameters. Results: Salivary mucin, amylase and protein levels were increased in patients with AgP and CP but there were no differences between them or between control groups. Pearson's correlation analysis, determined in the entire subjects studied, showed a positive and significant correlation of mucin, amylase and proteins with CAL and PPD and a negative correlation with the flow rate. When Pearson's correlation analysis was carried out in each group separately, Fisher's z transformation showed no significant difference between both groups. Conclusion: Comparison of the salivary levels of mucin, amylase and protein and their relationship with clinical parameters of AgP patients with that of $\mathrm{CP}$ patients revealed no differences between both groups.
\end{abstract}

Keywords: Mucins. Amylases. Aggressive periodontitis. Chronic periodontitis.

\section{INTRODUCTION}

Chronic and aggressive periodontitis consists of an inflammatory reaction of the periodontal tissues in response to infection caused by a specific group of bacteria. Aggressive periodontitis $(\mathrm{AgP})$ is characterized by severe and rapid loss of periodontal attachment, often commencing at or after the pubertyChronic periodontitis (CP) is a common disease that is prevalent among adults and seniors. The aggressive nature of AgP depends on the bacterial etiology, host susceptibility, hereditary and environmental factors, and often behavioral factors ${ }^{1}$.

There are numerous defense proteins present in saliva. Some of these defense proteins, such as salivary immunoglobulins, and salivary chaperokine HSP70/HSPA, are involved in both innate and acquired immune activation ${ }^{4,7}$. Salivary cationic peptides and other salivary defense proteins, such as lysozyme, BPI, BPI-like and PLUNC proteins, salivary amylase, cystatins, prolin-rich proteins, 
mucins, peroxidases, statherin (and others), are primarily responsible for innate immunity 4,5 notwithstanding that many of them also exert immune activator and/or immune modulator properties. Importantly, many of these molecules are present at rather low concentrations in whole saliva; however, it should be considered that their effects are cumulative and/or synergistic, resulting in an efficient molecular defense network of the oral cavity $4,5,13$. It should also be considered that local concentrations of these proteins near the mucosal surfaces (mucosal transudate), periodontal sulcus (gingival crevicular fluid) and oral wounds and ulcers (transudate) may be much greater, and in many cases are reinforced by immune and/ or inflammatory reactions of the oral mucosa ${ }^{6,7}$. Salivary glands may respond to oral disease by enhancing synthesis of some acinar proteins and thereby increasing the protective potential of saliva. Based on this line of reason, saliva from chronic periodontitis patients showed increased mucin and amylase concentration ${ }^{16}$.

Salivary mucin are heavily glycosylated high molecular weight glycoproteins produced by various mucous salivary glands, i.e. submandibular, sublingual and palatal glands and the minor salivary glands in the lip, cheek and tongue. Mucins play a major role in maintaining the viscoelastic properties of saliva. They also participate in forming a protective oral mucosal mucus coat and tooth enamel pellicle and have high affinity to microorganisms, entrapping and agglutinating bacteria, fungi and viral particles ${ }^{8}$.

Amylase is a highly abundant protein in saliva. The most widely-known function of amylase is its endoglicosidase activity, but in addition to his, amylase also takes part in acquired pellicle formation on tooth surfaces. It performs a direct inhibitory effect on the growth of certain bacteria and also binds to bacteria lipopolysaccharide, a bacterial surface structure and bacterial toxin, which are responsible in many cases for tissue destructive inflammatory reactions ${ }^{8}$. Thus, it was demonstrated that a-amylases from human saliva, porcine pancreas and rice show a significant cell growth inhibitory activity against Porphyromonas gingivalis species, and interfere with the adherence and biofilm formation of Aggregatibacter actinomycemcomitans, indicating that a-amylase could be effective in preventing periodontal diseases ${ }^{2,14}$.

Several studies have reported that the levels of distinct salivary proteins are altered in individuals with periodontal disease. Patients with gingivitis, $\mathrm{AgP}$ and $\mathrm{CP}$ showed increased salivary levels of mucin and amylase $2,9,11,16,19$. Conversely, other studies have reported a reduced expression of mucin glycoprotein-2 (MG2) and lactoferrin in unstimulated saliva from patients with $\mathrm{AgP}$ and $\mathrm{CP}^{15}$. Therefore, these results suggest that these salivary constituents may play a role in the etiopathogenesis of these diseases.

Since there are differences between $\mathrm{AgP}$ and $\mathrm{CP}$ not only in the clinical presentation ${ }^{10}$, the objective of this study was to investigate and compare the salivary levels of mucin and amylase and their relation with clinical parameters in patients with AgP and CP.

\section{MATERIAL AND METHODS}

\section{Study population}

Study subjects were recruited from a population of patients in a private dental clinic, from January through August 2014. The protocol was approved by the Ethics Committee of the School of Dentistry, University of Buenos Aires, Argentina, and the study was conducted in accordance with the Declaration of Helsinki (version 2008). Completed medical and dental histories were obtained from all subjects. The inclusion criteria for the study group were the presence of established AgP or $\mathrm{CP}$, according to World Workshop in Periodontology criteria $^{1}$, in subjects who had not had a periodontal checkup in the previous 6 months. Since there was a significant difference in the age between $\mathrm{AgP}$ and $\mathrm{CP}$ patients, two control groups were formed with subjects of similar ethnicity, income levels, age and gender to patients. All of the subjects gave their informed consent. Exclusion criteria included: smokers, those with cardiovascular or respiratory diseases, systemic inflammatory conditions or non-plaque induced oral inflammatory conditions, immunodeficiency, pregnant or breast feeding individuals and those using medicine.

\section{Clinical examination}

All periodontal measurements were performed in four quadrants using a first-generation probe (Hu-Friedy Mfg. Co., Chicago, IL, USA) by a single trained investigator (G.A.S.). Probing pocket depth (PPD, measurements were rounded off to the nearest millimetre marking) and clinical attachment level ( $C A L$, measuring the distance from the cemento-enamel junction to the bottom of the probable pocket) were assessed at six sites per tooth and bleeding on probing, (BOP, scored as: -, no bleeding or + , bleeding within $30 \mathrm{~s}$ after probing) at four sites per tooth.

\section{Saliva collection}

Unstimulated saliva was collected at 10 am the day after the periodontal diagnosis. Subjects were asked to refrain from eating or drinking two hours prior to collection. Whole saliva was collected by spitting into an ice-cooled graduated vessel. 
Subjects spat out saliva every 30 seconds for 5 minutes. The volume of saliva was recorded and expressed as $\mathrm{ml}$ per minute. The resulting saliva was stored in aliquots at $-20^{\circ} \mathrm{C}$ until determinations were performed.

\section{Determination of protein, amylase and mucin concentration \\ Colorimetric methods were used for all} determinations in unstimulated saliva. The protein concentration was determined by the method described by Lowry, et al. ${ }^{12}$ (1951) and the amylase activity was determined in diluted saliva (1/100) by the method described by Bernfeld ${ }^{3}$ (1951) using starch suspension as the substrate. Amylase activity is expressed in terms of Units (U) where $1 \mathrm{U}$ of amylase was defined as the quantity of enzyme that liberates $1 \mathrm{mg}$ of maltose for $1 \mathrm{~min}$ at $20^{\circ} \mathrm{C}$. Mucin concentration was determined using the Alcian blue method $^{16}$. Briefly, aliquots of diluted saliva (1:10) were incubated for $30 \mathrm{~min}$ in a $1 \%$ solution of Alcian Blue in $50 \mathrm{mM}$ sodium acetate buffer with $25 \mathrm{mM}$ $\mathrm{Cl}_{2} \mathrm{Mg}$, pH 5.8 under constant agitation at room temperature. Following incubation, the samples were centrifuged for $20 \mathrm{~min}$ at $3000 \mathrm{rpm}$, pellets washed in $95 \%$ ethanol, vortexed gently for $10 \mathrm{~s}$ and after $5 \mathrm{~min}$ centrifuged for $20 \mathrm{~min}$ at $3000 \mathrm{rpm}$. Mucin-dye complexes were dissociated by adding a $1: 2$ dilution of Aerosol OT (Sigma Chemical Co., St Louis, MO, USA) in distilled water, brief mixing and sonication. Subsequently, samples were extracted with equal volumes of ethyl ether through vigorous shaking. The resulting solution was centrifuged for $15 \mathrm{~min}$ at $3000 \mathrm{rpm}$ and the dye concentration was spectrophotometrically determined at $605 \mathrm{~nm}$ in the aqueous layer.

\section{Statistical analysis}

Statistical significance of differences was determined by one way ANOVA followed by NeumanKeuls multiple comparison test. Pearson correlation analysis were done using GRAPHPAD Prism version 5.03 for Windows (GraphPad Software, San Diego, CA, USA) and Fisher's z transformation, which converts Pearson's $r$ to the normally distributed variable $z$, was used to assess the significance of the difference between the $r$. The level of statistical significance is set to $p<0.05$.

\section{RESULTS}

Demographic and clinical data from patients with $\mathrm{AgP}$ and $\mathrm{CP}$ are presented in Table 1. Due to the difference in age of the two disease groups, each of them was matched with subjects representing two control groups. As can be seen in the table, both disease groups showed significantly higher CAL and PPD but lower unstimulated flow rate than the control groups, when tested by one-way ANOVA followed by Neuman-Keuls multiple comparison

Table 1- Demographic and clinical data from patients with aggressive (AgP) and chronic (CP) periodontitis and their matched controls

\begin{tabular}{|c|c|c|c|c|}
\hline Parameter/Group & Control AgP & Patients AgP & Control CP & Patients CP \\
\hline $\begin{array}{c}\text { Age: mean/range } \\
\text { (years) }\end{array}$ & $19.5 / 17-23$ & $19.5 / 17-23$ & $37.4 / 32-40$ & $37.4 / 32-40$ \\
\hline Gender & Female: 10 Male: 10 & Female: 10 Male: 10 & Female: 10 Male: 10 & Female: 10 Male: 10 \\
\hline $\begin{array}{c}\text { Number of teeth } \\
\text { (range) }\end{array}$ & $28-30$ & $28-30$ & $28-30$ & $26-28$ \\
\hline $\begin{array}{c}\text { Number of sites } \\
\text { checked up }\end{array}$ & $168-180$ & $168-180$ & $168-180$ & $156-168$ \\
\hline $\mathrm{CAL}(\mathrm{mm})$ & $0.23 \pm 0.06$ & a5. $9 \pm 0.17^{* * *}$ & $0.25 \pm 0.06$ & $4.2 \pm 0.35^{\star * *}$ \\
\hline $\begin{array}{c}\text { Number of sites CAL } \\
>4 \mathrm{~mm} \text { (median/ } \\
\text { range) }\end{array}$ & 0 & $5 / 0-6$ & 0 & $3 / 0-5$ \\
\hline PPD (mm) & $2.4 \pm 0.06$ & b5 $5 \pm 0.07^{* * *}$ & $2.5 \pm 0.06$ & $5.1 \pm 0.2^{* * *}$ \\
\hline $\begin{array}{c}\text { Number of sites PPD } \\
>5 \mathrm{~mm} \text { (median/ } \\
\text { range) }\end{array}$ & 0 & $3 / 0-5$ & 0 & $3 / 0-5$ \\
\hline UFR (ml/min) & $0.54 \pm 0.01$ & $0.44 \pm 0.02^{* * *}$ & $0.53 \pm 0.01$ & $0.47 \pm 0.01^{* \star *}$ \\
\hline
\end{tabular}

Data are the mean \pm SEM. CAL: clinical attachment level; PPD: probing pocket depth; UFR: salivary unstimulated flow rate. ${ }^{* * *}$ significantly different from controls, $p<0.001$; a: significantly different from CP $p<0.001$; $b$ : significantly different from $\mathrm{CP}, \mathrm{p}<0.01$ 
A

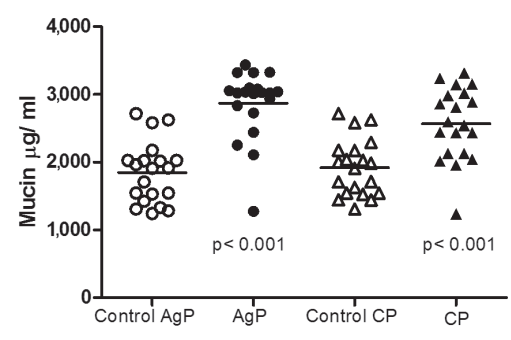

B

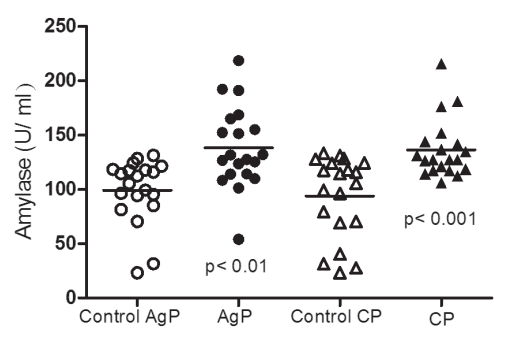

C

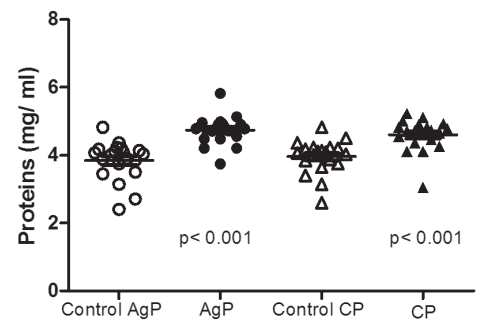

Figure 1- Salivary levels of mucin (A), amylase (B) and proteins (C) in unstimulated saliva from patients with aggressive and chronic periodontal disease and their matched controls

A

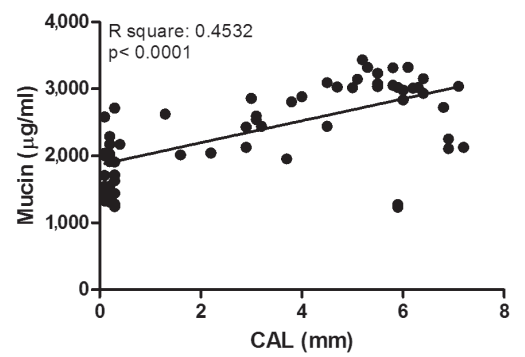

B

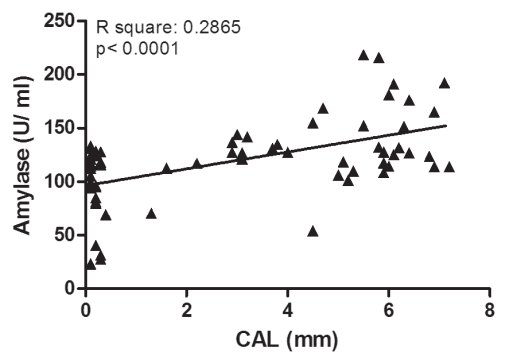

C

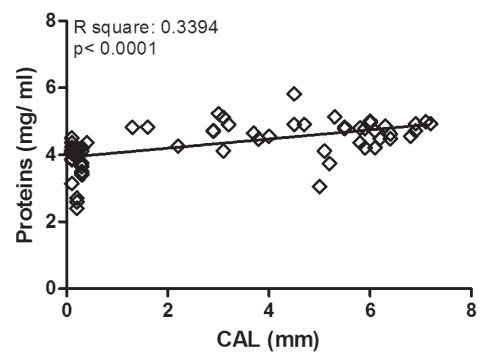

Figure 2- Pearson's correlation analysis between mucin (A), amylase (B) and proteins (C) and clinical attachment level (CAL) in the entire subjects studied

A

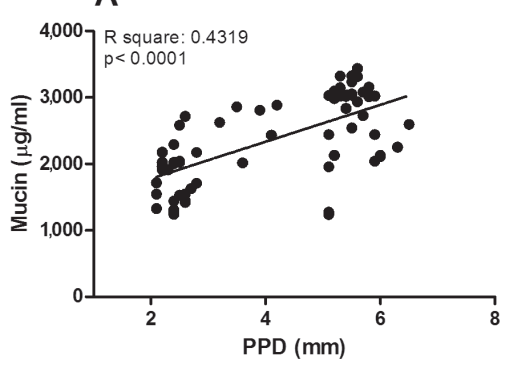

B

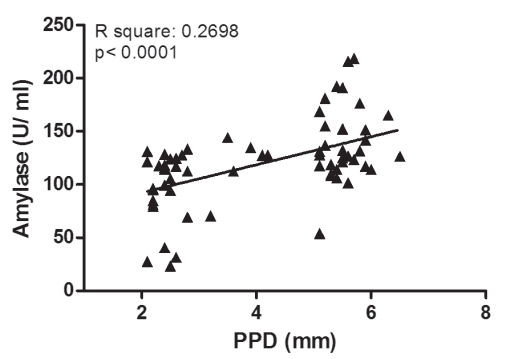

C

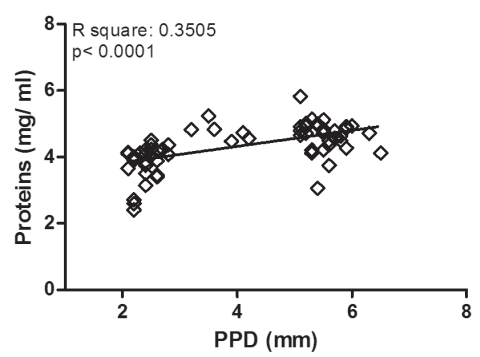

Figure 3- Pearson's correlation analysis between mucin (A), amylase (B) and proteins (C) and probing pocket depth (PPD) in the entire subjects studied

A

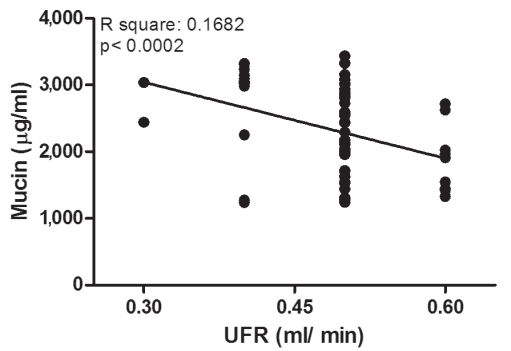

B

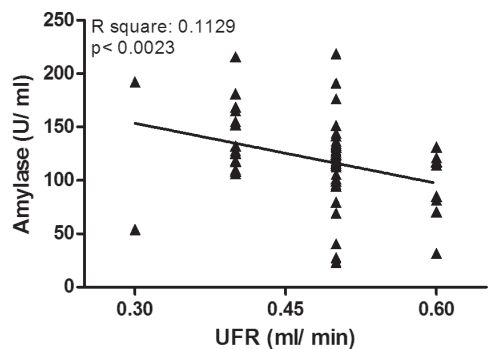

C

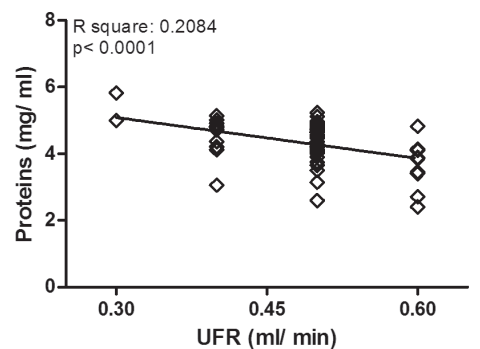

Figure 4- Pearson's correlation analysis between mucin (A), amylase (B) and proteins $(C)$ and salivary unstimulated flow rate (UFR) in the entire subjects studied 
test. Patients with AgP had more periodontal destruction than patients with $\mathrm{CP}$, as evidenced from the higher CAL and PPD observed.

The levels of mucin, amylase and proteins in unstimulated saliva differed widely in the patient and control groups. There was a significantly higher mucin, amylase and protein concentration in saliva from patients with aggressive and chronic periodontitis than in the control groups (Figures $1 \mathrm{~A}, \mathrm{~B}$ and $\mathrm{C}$ ). On the other hand, there were no differences between the control groups or disease groups.
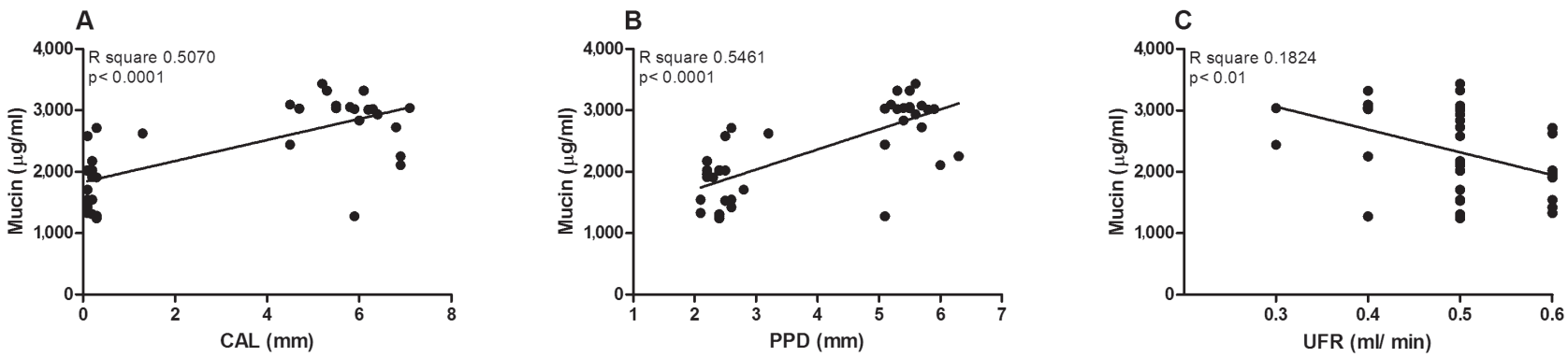

\section{D}
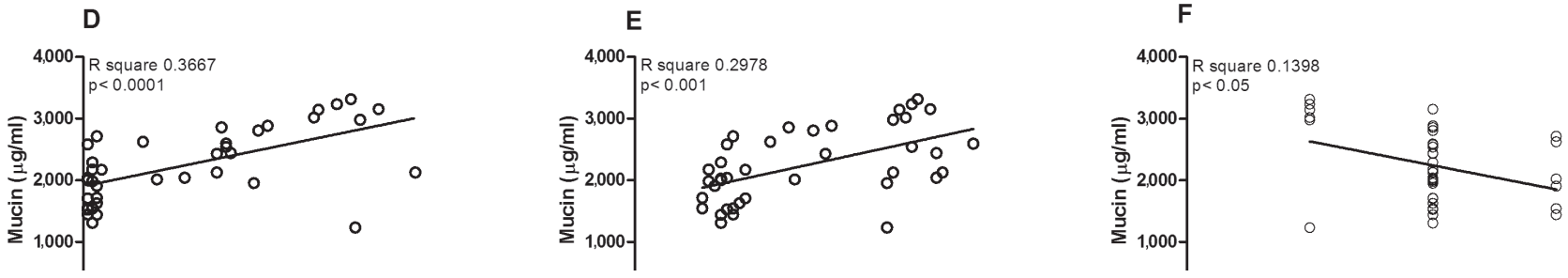

Figure 5- Pearson's correlation analysis between mucin and clinical attachment level (CAL) (A and D), probing pocket depth (PPD) (B and E) and unstimulated flow rate (UFR) (C and F) in aggressive periodontitis (AgP) (upper panel) and chronic periodontitis (CP) (lower panel) groups
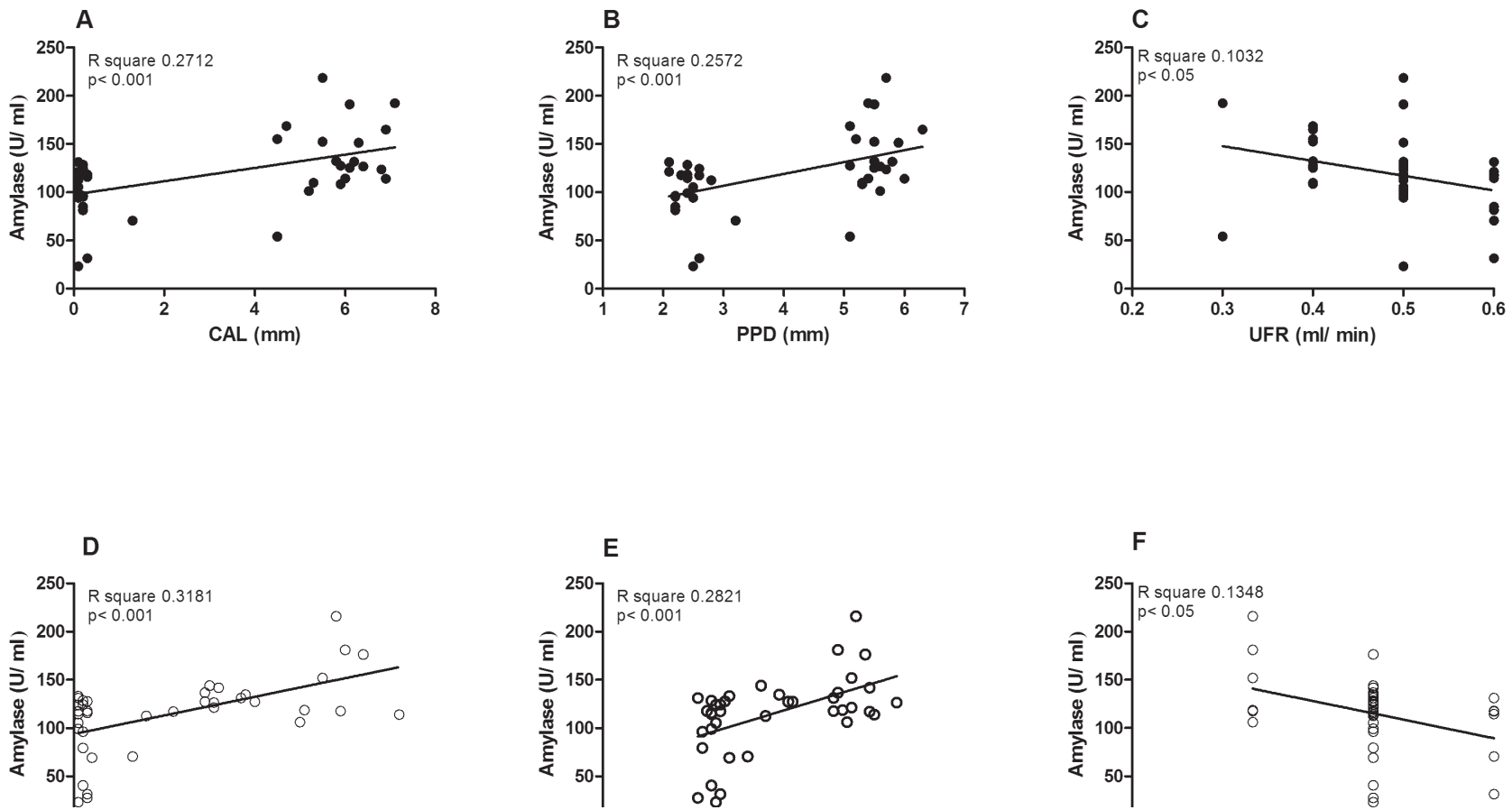

Figure 6- Pearson's correlation analysis between amylase and clinical attachment level (CAL) (A and D), probing pocket depth (PPD) (B and E) and unstimulated flow rate (UFR) (C and F) in aggressive periodontitis (AgP) (upper panel) and chronic periodontitis (CP) (lower panel) groups 
A

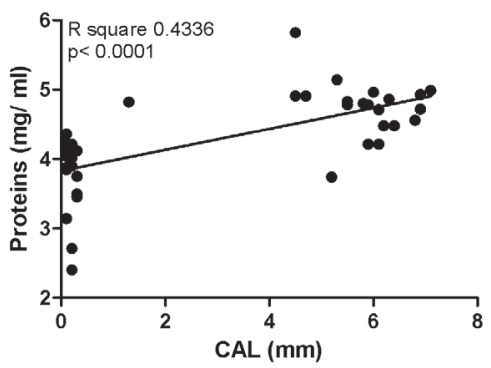

D

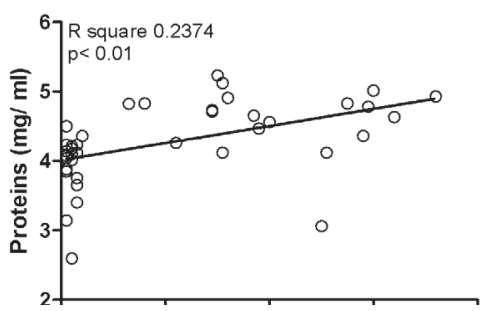

B

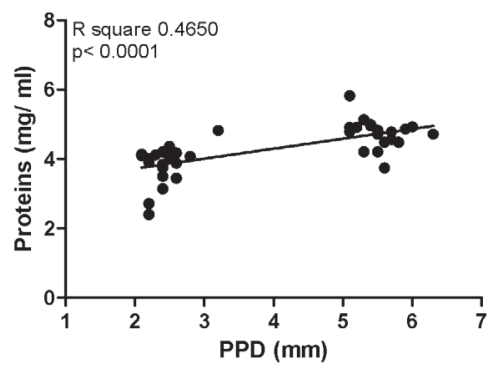

E

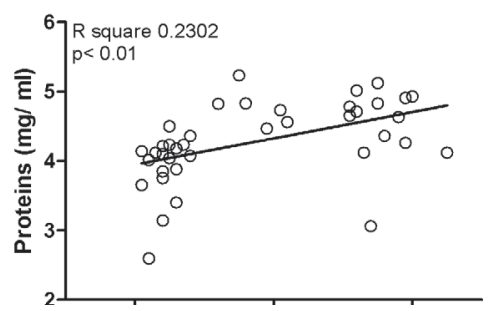

C

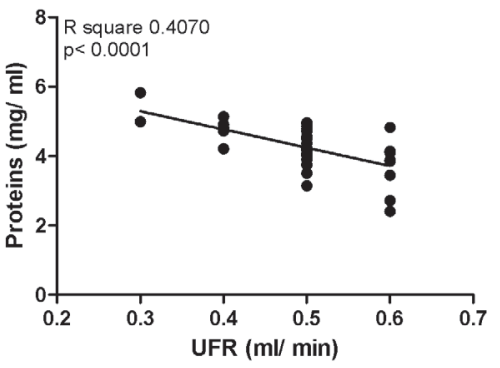

F

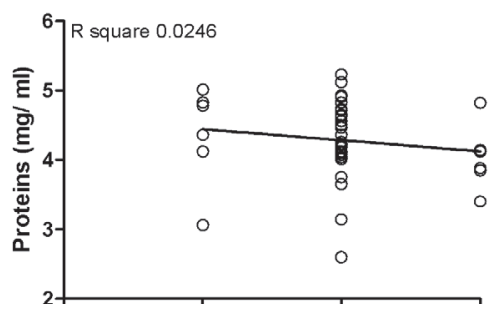

Figure 7- Pearson's correlation analysis between total proteins and clinical attachment level (CAL) (A and D), probing pocket depth (PPD) (B and E) and unstimulated flow rate (UFR) ( $C$ and $F$ ) in aggressive periodontitis (AgP) (upper panel) and chronic periodontitis (CP) (lower panel) groups

The correlations, among the levels of mucin, amylase and proteins and the clinical parameters, determined in all studied subjects, are shown in Figures 2, 3 and 4. The salivary mucin, amylase and protein concentration was positively correlated with CAL (Figure 2) and PPD (Figure 3). Conversely, a significant but negative correlation was observed between the salivary levels of mucin, amylase and proteins and the unstimulated flow rate. The correlations, despite being significant, were weak. On the other hand, the comparison by Fisher's $z$ transformation between those correlations showed no significant differences.

In order to determine whether there were differences between the AgP and CP groups, based on the relationship among mucin, amylase and proteins and the clinical parameters, Pearson's correlation analysis was carried out in each group separately (Figures 5 to 7). Fisher's z transformation showed that there was no significant difference between both groups ( $p>0.05)$, the only exception being the correlation between UFR and proteins $(p<0.01)$.

\section{DISCUSSION}

In this study, the relationship between salivary mucin, amylase and protein levels and clinical parameters in patients with $\mathrm{AgP}$ and $\mathrm{CP}$ were compared. Unstimulated saliva were used because there is a prevalent resting condition in the oral cavity for most of the 24-hour period and, as the salivary secretion is a reflex response, it can be influenced by several stimuli such as the accumulation of plaque-derived substances or inflammatory products $^{18}$. Thus, a positive relationship between basal values of mucin, amylase and proteins with CAL and PPD would be expected ${ }^{17}$. As a matter of fact, there is evidence that the salivary glands may respond to periodontitis by enhanced synthesis of some acinar proteins and thereby an increase in the protective potential of saliva9,11,16.

Both patient groups showed higher CAL and PPD but la ower flow rate than the control groups. Patients with AgP showed higher CAL and PPD than patients with $C P$, without differences in unstimulated flow rate.

Levels of mucin, amylase and proteins in saliva from adults with or without chronic periodontal disease were evaluated in a previous study ${ }^{16}$. A higher concentration of mucin, amylase and proteins were found in saliva from patients compared with healthy subjects. This study was undertaken to determine whether there were any differences between AgP and CP. The results showed that patients with AgP presented similar levels of mucin, amylase and proteins than patients with CP and because unstimulated flow rate was similar in both groups, this result must not be attributed to a different volume of saliva.

As previously described ${ }^{17}$, a positive and significant correlation was observed between mucin, 
amylase and protein with CAL and PPD. This fact is in accordance with the hypothesis that inflammatory products may trigger salivary secretion via neural pathways ${ }^{18}$. When correlations were made in each group separately, no differences between AgP and PC were found.

It is known that $\mathrm{AgP}$ differs from $\mathrm{CP}$ not only in bacterial aetiology, but also in host immune and inflammatory factors implicated in the pathogenesis and progression of AgP. The presence of neutrophil abnormalities ${ }^{16}$ and a reduced total IgA, described in subjects with $\mathrm{AgP}^{8}$, reflects a general downregulation of the humoral immune system. However, as derived from our results, it can be concluded that there are no differences between AgP and CP in relation to mucin, amylase and protein salivary levels. In both clinical manifestations of the disease the increase in mucin, amylase and protein concentrations is influenced by clinical parameters.

\section{CONCLUSION}

Comparison of the salivary levels of mucin, amylase and protein and their relationship with clinical parameters of AgP patients with that of $\mathrm{CP}$ patients revealed no differences between both groups.

\section{ACKNOWLEDGMENTS}

This work was supported by Grant UBACYT No 20020110100135. The authors have no conflict of interest to disclose.

\section{REFERENCES}

1- Armitage GC. Development of a classification system for periodontal diseases and conditions. Ann Periodontol. 1999;4:1-6. 2- Baik JE, Hong SW, Choi S, Jeon JH, Park OJ, Cho K, et al. Alpha-amylase is a human salivary protein with affinity to lipopolysaccharide of Aggregatibacter actinomycemcomitans. Mol Oral Microbiol. 2013;28:142-53.

3- Bernfeld P. Enzymes of starch degradation and synthesis. Adv Enzymol Relat Subj Biochem. 1951;12:379-428.

4- Fábián TK, Fejérdy $P$, Csermely P. Saliva in health and disease, chemical biology of. In: Begley TP, ed. Wiley encyclopedia of chemical biology. Hoboken: John Wiley \& Sons, Inc.; 2008. vol. 4, p. 1-9.
5- Fábián TK, Fejérdy P, Csermely P. Salivary genomics, transcriptomics and proteomics: the emerging concept of the oral ecosystem and their use in the early diagnosis of cancer and other diseases. Curr Genomics. 2008;9:11-21

6- Fábián TK, Fejérdy P, Nguyen MT, Söti C, Csermely P. Potential immunological functions of salivary Hsp70 in mucosal and periodontal defense mechanisms. Arch Immunol Ther Exp (Warsz). 2007;55:91-8.

7- Fábián TK, Gótai L, Beck A, Fábián G, Fejérdy P. The role of molecular chaperones (HSPAs/HSP70s) in oral health and oral inflammatory diseases: a review. Eur J Inflamm. 2009;7:53-61. 8- Fábián TK, Hermann P, Beck A, Frejérdy P, Fábián G. Salivary defense proteins: their network and role in innate and acquired oral immunity. Int J Mol Sci. 2012;13:4295-320.

9- Henskens YM, van den Keijbus PA, Veerman EC, Van der Weijden GA, Timmerman MF, Snoek CM, et al. Protein composition of whole and parotid saliva in healthy and periodontitis subjects. Determination of cystatins, albumin, amylase and IgA. J Periodontal Res. 1996;31:57-65.

10- Highfield J. Diagnosis and classification of periodontal disease. Aust Dent J. 2009;54:S11-26.

11- Kejriwal S, Bhandary R, Thomas B, Kumari S. Estimation of levels of salivary mucin, amylase and total protein in gingivitis and chronic periodontitis patients. J Clin Diagn Res. 2014;8:ZC56-60. 12- Lowry $\mathrm{OH}$, Rosebrough NJ, Farr AL, Randall R. Protein measurement with the Folin phenol reagent. J Biol Chem. 1951; 193:267-75

13- Madhwani T, McBain AJ. Compositional modification of nascent in vitro dental plaques by human host-defence peptides. FEMS Immunol Med Microbiol. 2012;64:374-81.

14- Ochiai A, Harada K. Hashimoto K, Shibata K, Ishiyama Y, Mitsui $\mathrm{T}$, et al. a-Amylase is a potential growth inhibitor of Porphyromonas gingivalis, a periodontal pathogenic bacterium. J Periodont Res. 2014;49:62-8.

15- Rocha DM, Zenóbio EG, Van Dyke T, Silva KS, Costa FO, Soares RV. Differential expression of salivary glycoproteins in aggressive and chronic periodontitis. J Appl Oral Sci. 2012;20:180-5.

16- Sánchez GA, Miozza V, Delgado A, Busch L. Determination of salivary levels of mucin and amylase in chronic periodontitis patients. J Periodontal Res. 2011;46:221-7.

17- Sánchez GA, Miozza VA, Delgado A, Busch L. Relationship between salivary mucin or amylase and the periodontal status. Oral Dis. 2013;19:585-91.

18- Seeman R, Hägewald SJ, Sztankay V, Drews J, Bizhang M, Kage A. Levels of parotid and submandibular/sublingual salivary immunoglobulin $A$ in response to experimental gingivitis in humans. Clin Oral Invest. 2004;8:233-7.

19- Wu Y, Shu R, Luo LJ, Ge LH, Xie YF. Initial comparison of proteomic profiles of whole unstimulated saliva obtained from generalized aggressive periodontitis patients and healthy control subjects. J Periodont Res. 2009;44:636-44. 